Vol.02/ No. 03

Pages: $147-155$

https://www.irojournals.com/iroiip/

DOI: https://doi.org/10.36548/jiip.2020.3.005

\title{
Iris Image Segmentation and Localization using Dynamic Reconfigurable Processor
}

\author{
Smaran S Rao ${ }^{1}$, Shreyas R ${ }^{1}$, Gajanan Maske ${ }^{2}$, Antara Roy Choudhury ${ }^{\text {* }}$ \\ ${ }^{1}$ Department of Computer Science and Engineering, BMS College of Engineering, Bengaluru, India \\ ${ }^{2}$ Senior Technical Lead, PathPartner Technology, Bengaluru, India \\ E-mail: *antararc.cse@bmsce.ac.in
}

\begin{abstract}
Recognition of the Iris is among the finest techniques in the field of bio-metrics identification, because the iris has characteristics that are unique and stay the same all through the individual's life. Iris recognition phases are namely image acquisition, segmentation of iris, localization of iris, feature extraction of iris and matching. This paper, which is an extension of the survey paper Smaran et.al[1], concentrates purely on the procedures of image capture, segmentation as well as localization of the iris. The aim of the paper is to optimize the above mentioned processes in terms of distance of capturing the image, time taken for memory and computation requirements, using the DRP (Dynamic Re-Configurable Processor) technology, uniquely developed by Renesas Electronics (www.renesas.com).
\end{abstract}

Keywords: Bio-metric; Iris; Image; Segmentation; Localization; Optimization

\section{Introduction}

Iris is a fine and secure portion of the eye, that gives a distinctive bio-metric characteristic which is preserved all through the individual's life. Rechu et.al[2] have stated that the recognition of iris consists of functions like image acquisition, segmentation, localization, normalization, encoding and template matching of the image. Acquisition of image refers to acquiring the image from the source. The process of segmentation refers to retrieving different parts of the eye namely diameter of pupil, eyelid and eyelashes, etc. so that for further processing, storing this information will be useful. Localization of image refers to picking up the bio-metric characteristics for different coordinates of the image. Normalization is the retrieval of the basic feature vector, following segmentation and localization of various segments of the iris. The procedure of encoding of the image, is the bit code encoding of the different distinguished patterns of iris. Matching of the image is basically the checking for the match of the encoded value with previous values present in the database. This paper will describe up to the process of localization of image. Localization and segmentation of iris are salient stages of the process of recognition of iris, as a bulk of the processing of the image is performed in these stages, in order to prepare for the procedure of feature extraction. If these initial processes are not accurate or consume a lot of time, the procedures of feature extraction as well as matching are either delayed further or not accurate. Therefore, Renesas's Dynamic Re-Configurable processor (DRP) technology is introduced in this paper, along with image processing algorithms based on DRP, that reduce the space and time complexities of the procedures. The technology implements faster execution while using parallel processing, performs CPU (Central Processing Unit) loading and offloading dynamically, as well as consumes less power. Section 3 provides a detailed description of DRP. The primary motivation is the adoption of a new, efficient and effective technology to an engaging and necessary domain of bio-metrics. The aims are to create a user friendly system, decrease the space and time complexities for image processing of the iris, in comparison to current CPU based systems. The objective is also providing the utmost quality possible of the image for the further procedures of iris recognition. This paper further contains the following sections: Section 2 for a Literature Review, Section 3 for Implementation being proposed, Section 4 for Results, Section 5 for Conclusion and Future Enhancements, followed by the Acknowledgment and finally the References. 
Journal of Innovative Image Processing (JIIP) 2020)

Vol.02/ No. 03

Pages: $147-155$

https://www.irojournals.com/iroiip/

DOI: https://doi.org/10.36548/jiip.2020.3.005

\section{Related Works}

This paper talks about the current frameworks and work done in the periods of image capture, image segmentation and image localization of pictures of irises. Table 1 gives a short examination of different usages for the image capture stage.

\begin{tabular}{|c|l|l|}
\hline \multicolumn{1}{|c|}{ Reference } & \multicolumn{1}{|c|}{ Distance of camera from user } & \multicolumn{1}{c|}{ Supplementary information } \\
\hline Supriya et.al[3] & Less than $35 \mathrm{~cm}$ (centimeter) & Range of illumination -320 to 500 lx (lux) \\
\hline Hazra et.al[4] & 5 to 10 inches $(12.7 \mathrm{~cm}-25.4 \mathrm{~cm})$ & 1 to 2 seconds for Image Capture phase \\
\hline Thomas et.al[5] & 6 inches $(15.24 \mathrm{~cm})$ & $\begin{array}{l}\text { LG EOU200 system, with 3 IR (Infra Red) LEDs (Light } \\
\text { Emitting Diodes), is used. }\end{array}$ \\
\hline
\end{tabular}

Table 1 : Different usages of Image Capture stage

The reason for the image segmentation stage is to precisely find the iris region from the picture of the whole eye caught. Table 2 shows the different strategies actualized, alongside their portrayals, qualities, points of interest and deficiencies.

\begin{tabular}{|c|c|c|c|c|c|}
\hline Reference & Method & Description & Characteristics & Advantages & Shortcomings \\
\hline $\begin{array}{l}\text { Sruthi } \\
\text { et.al[6] }\end{array}$ & Region Growing & $\begin{array}{l}\text { Direct } \\
\text { construction of } \\
\text { regions }\end{array}$ & $\begin{array}{l}\text { Suitable for noisy } \\
\text { images where edges } \\
\text { are hard to detect }\end{array}$ & $\begin{array}{l}\text { Correctly } \\
\text { separates regions } \\
\text { having the same } \\
\text { property }\end{array}$ & $\begin{array}{l}\text { Time consuming } \\
\text { algorithm }\end{array}$ \\
\hline $\begin{array}{c}\text { Kumaresan } \\
\text { et.al[7] }\end{array}$ & $\begin{array}{ll}\text { Genaralized } & \\
\text { Structure } & \text { Tensor } \\
(\text { GST }) & \end{array}$ & $\begin{array}{l}\text { Boundary of the } \\
\text { pupil is detected } \\
\text { first }\end{array}$ & $\begin{array}{l}\text { Uses circular } \\
\text { complex filters to } \\
\text { identify mismatch, } \\
\text { which is absent in } \\
\text { other methods }\end{array}$ & $\begin{array}{l}\text { Local shifting of } \\
\text { edge locations is } \\
\text { minimized. Better } \\
\text { description of } \\
\text { local patterns. }\end{array}$ & $\begin{array}{l}\text { Time consuming } \\
\text { to detect the pupil } \\
\text { boundary first. }\end{array}$ \\
\hline Banu et.al[8] & $\begin{array}{l}\text { Coarse } \\
\text { Segmentation }\end{array}$ & $\begin{array}{l}\text { Provides simple } \\
\text { classification. }\end{array}$ & $\begin{array}{l}\text { Might not provide a } \\
\text { very high accuracy } \\
\text { due to simplicity }\end{array}$ & $\begin{array}{l}\text { Easy to } \\
\text { implement and } \\
\text { time efficient }\end{array}$ & Low accuracy \\
\hline $\begin{array}{l}\text { Anandhi } \\
\text { et.al[9], } \\
\text { Murthy } \\
\text { et.al[10], } \\
\text { Pardhi } \\
\text { et.al[11] }\end{array}$ & $\begin{array}{l}\text { Canny Edge } \\
\text { Detection }\end{array}$ & $\begin{array}{l}\text { Used to obtain the } \\
\text { major edges of } \\
\text { the image }\end{array}$ & $\begin{array}{l}\text { Smoothens the image } \\
\text { to remove noise and } \\
\text { improves signal to } \\
\text { noise ratio }\end{array}$ & $\begin{array}{l}\text { Most commonly } \\
\text { used because of } \\
\text { its robustness }\end{array}$ & $\begin{array}{l}\text { Complex } \\
\text { computation and } \\
\text { time consuming }\end{array}$ \\
\hline
\end{tabular}

Table 2 : Summary of segmentation methods 
Journal of Innovative Image Processing (JIIP) 2020)

Vol.02/ No. 03

Pages: $147-155$

https://www.irojournals.com/iroiip/

DOI: https://doi.org/10.36548/jiip.2020.3.005

The last stage that this paper centers around is that of image localization. It targets confining the most significant highlights of the iris picture precisely, for additional processes. Table 3 furnishes the different strategies executed alongside their qualities, favorable circumstances and draw backs.

\begin{tabular}{|c|l|l|l|l|}
\hline Reference & \multicolumn{1}{|c|}{ Method } & \multicolumn{1}{c|}{ Characteristics } & \multicolumn{1}{c|}{ Advantages } & \multicolumn{1}{c|}{ Limitations } \\
\hline Rajasri et.al[12] & Integro Differential & $\begin{array}{l}\text { Used to detect inner and } \\
\text { outer boundaries of iris and } \\
\text { both upper and lower eyelids }\end{array}$ & Faster computation & $\begin{array}{l}\text { Lesser accuracy } \\
\text { compared to Hough } \\
\text { Transform }\end{array}$ \\
\hline $\begin{array}{c}\text { Walia et.al[13], } \\
\text { Rana et.al[14] }\end{array}$ & Hough Transform & $\begin{array}{l}\text { Uses a selective threshold } \\
\text { value to figure out the edges }\end{array}$ & $\begin{array}{l}\text { Conceptually simple } \\
\text { technique }\end{array}$ & $\begin{array}{l}\text { Computationally } \\
\text { intensive and not for } \\
\text { real time problems }\end{array}$ \\
\hline $\begin{array}{c}\text { Richard } \\
\text { et.al[15] }\end{array}$ & Bisection Method & $\begin{array}{l}\text { Finds the center of the pupil, } \\
\text { to use as reference to find } \\
\text { edges }\end{array}$ & $\begin{array}{l}\text { Useful to avoid noise } \\
\text { of eyelid and eyelash }\end{array}$ & $\begin{array}{l}\text { Not suitable for } \\
\text { illusion and glass } \\
\text { reflection }\end{array}$ \\
\hline $\begin{array}{l}\text { Richard } \\
\text { et.al[15] }\end{array}$ & $\begin{array}{l}\text { Discrete circular } \\
\text { active contour }\end{array}$ & $\begin{array}{l}\text { A simple closed curve called } \\
\text { contour is created and } \\
\text { moved to capture a perfect } \\
\text { circle }\end{array}$ & $\begin{array}{l}\text { Better performance } \\
\text { for objects with weak } \\
\text { edges }\end{array}$ & Long runtime \\
\hline $\begin{array}{l}\text { Richard } \\
\text { et.al[15] }\end{array}$ & Black Hole search & $\begin{array}{l}\text { Used to compute center and } \\
\text { area of pupil }\end{array}$ & High accuracy rate & $\begin{array}{l}\text { Computationally } \\
\text { intensive }\end{array}$ \\
\hline
\end{tabular}

Table 3 : Summary of localization methods

Taking everything into account, the general downside of the current framework for the mentioned procedures, lies in the fact that it is both memory and time concentrated. The camera catches a picture, relays it to a PC (Personal Computer) consisting of a CPU, which runs the calculations and algorithms. These calculations talked about in this paper, have their focal points and hindrances. In conclusion, a successful and proficient strategy is required which occupies less room in the memory and does complex scientific calculations quicker.

\section{Proposed Work}

In the methodology recommended in this paper, rather than a customary CPU, a DRP based equipment will be utilized which diminishes the RAM (Random Access Memory) use, builds productivity of numerical calculations and diminishes computational chance to process complex calculations. The Dynamic Reconfigurable Processor innovation by Renesas, is a special equipment incorporated with Micro-processor units (MPU), that drastically speeds up image processing calculations by multiple times. It consolidates high execution of equipment arrangements with adaptability and development usefulness of a CPU. The arrangement comprises of a camera, IR LED board and Misano board. DC (Direct Current) power is utilized to control the board with the necessary voltage. The yield of the camera buffer can be shown on a monitor. The lens utilized to take pictures is EV1620KV.

DRP guarantees decreased time and space complexity through the following methodologies:

1) Dynamic reconfiguration:

- DRP has the ability to allow switching between multiple statistics paths, in every clock cycle. 
Journal of Innovative Image Processing (JIIP) 2020)

Vol.02/ No. 03

Pages: $147-155$

https://www.irojournals.com/iroiip/

DOI: https://doi.org/10.36548/jiip.2020.3.005

- Without having the need to expand the hardware, time and space multiplexing is able to execute complex algorithms, with fixed DRP areas, for enhancing the performance.DRP can speed up distinct multiple algorithms in the application.

2) Dynamic Loading:

- DRP can quicken multiple distinct algorithms utilized in the application.

- New and fresh configurations are able to be loaded as quickly as $1 \mathrm{~ms}$.

The detailed design diagram can be seen in Figure 1 and each module is discussed below.

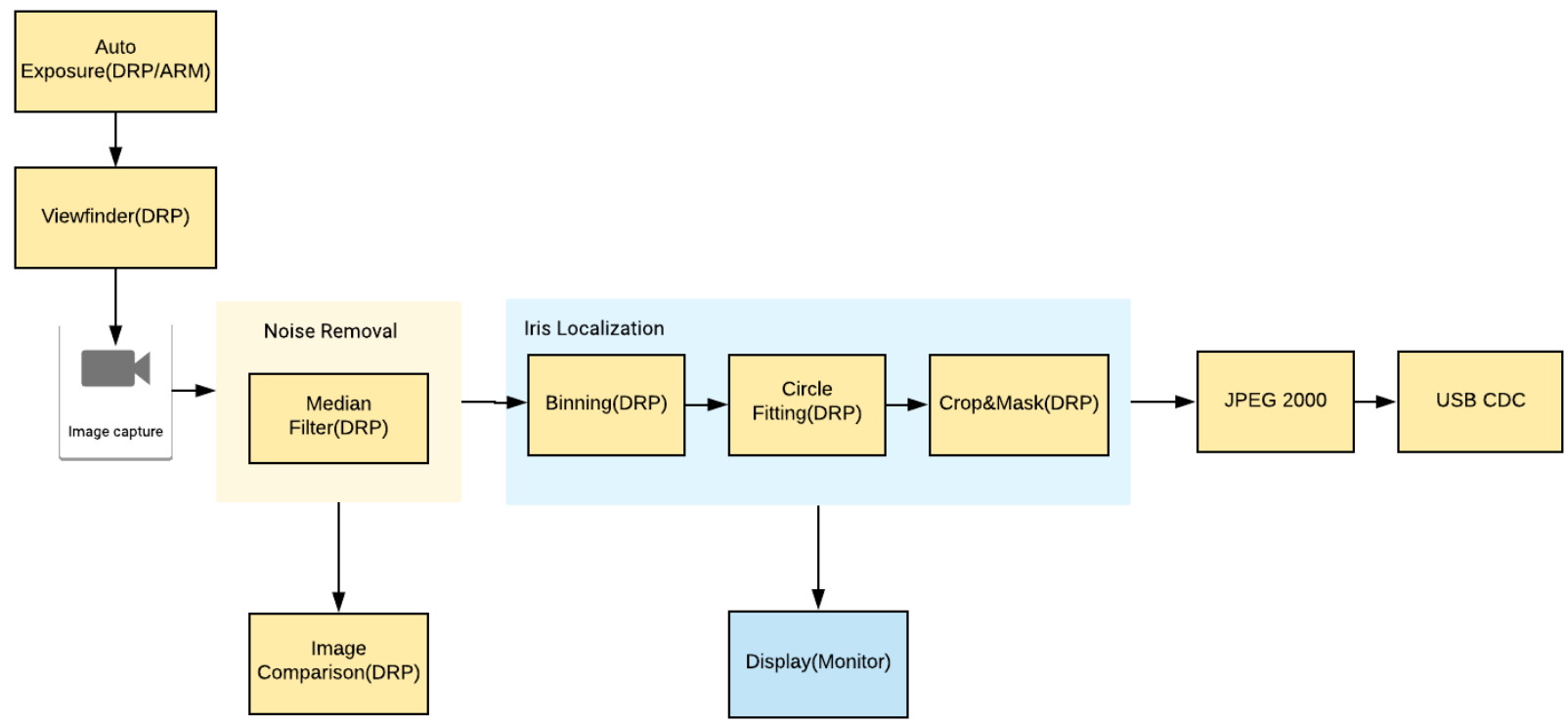

Figure 1 : Detailed Design

\subsection{Auto Exposure:}

This module computes exposure and gain for image sensors progressively, in view of scene lighting conditions. Auto exposure initially registers image insights and afterward actualizes control rationale to determine exposure and gain. Auto Exposure calculation figures the nearby mean of regions in a picture. The picture is divided into $4 \times 4$ regions according to the field of view and loads are allotted to every region, with the center given a higher weight. The mean of every region is processed and weights are utilized to get a single value of brightness. When the mean of the picture is determined, it is compared against the threshold value. The image is said to be overexposed if the error is positive and underexposed if it is negative. If the value is within the threshold, it is taken as "Exposure OK", which is ideal to process further.

\subsection{View Finder:}

To ensure that the user is in focus, View Finder module based on Sobel Filter is executed. Sobel filter based histogram examination can be utilized to locate the best focal point of the picture. If the picture is in the ideal focus, majority of the values tend to be below the threshold. In the event that the picture is out of focus, at that point majority of the values will be more than the histogram threshold. 
Journal of Innovative Image Processing (JIIP) 2020)

Vol.02/ No. 03

Pages: $147-155$

https://www.irojournals.com/iroiip/

DOI: https://doi.org/10.36548/jiip.2020.3.005

\subsection{Median Filter:}

A Median Filter is a non-linear filter that is utilised for signal smoothing. It's motivation here is to expel noise from the picture avoiding loss of edges. The non-linear function can be communicated as equation (1):

$y(n)=\operatorname{med}[x(n-k), x(n-k+1), \ldots, x(n), \ldots, x(n+k-1), x(n+k)]$

where,

- $\mathrm{y}(\mathrm{n})=$ output signal

- $\quad \mathrm{x}(\mathrm{n})=$ input signal

- $\quad$ Filter Length $=2 \mathrm{k}+1$

\subsection{Image Comparison:}

To lessen detection of false circles in the captured picture, 32x32 px (Pixels) sized boxes are set on the iris and a single $32 \times 32$ px sized box on the sclera area. Average value of every region is found and a score is determined by the equation, Score $=$ Mean $(B 3)-$ Mean of $(B 2+B 1)$. This is interchangeable to the segmentation stage.

Pictures with iris have bigger score when contrasted to pictures without it. Refer Figure 2 for a portrayal of the regions.



Figure 2 : Portrayal of Image Comparison

\subsection{Binning:}

Yield of the Median Filter module is given to the Binning module. It lessens the picture width and picture height considerably, which diminishes the complexity of the circle fitting calculation. DRP based module is utilized for quicker handling.

\subsection{Circle Fitting:}

The Circle Fitting calculation comprises of two sections discussed below. The first one, Circle Fitting Rough, gets it's input from the binning module and creates rough estimation of center coordinates and radius of the circle present in the picture. This estimate is then given to the Circle Fitting Fine module alongside the yield of middle filter, which at that point yields accurate center coordinates and radius of the circle. DRP based modules are utilized for quick handling. This is interchangeable to the image localization stage. 
Journal of Innovative Image Processing (JIIP) 2020)

Vol.02/ No. 03

Pages: $147-155$

https://www.irojournals.com/iroiip/

DOI: https://doi.org/10.36548/jiip.2020.3.005

\subsection{Crop and Mask:}

A solitary DRP module performs masking and cropping. The contribution to this module is the captured picture and the circle parameters namely the center coordinates and radius. Utilizing these circle boundaries, measurements such as total height and width of cropped image are found. Masking is done to improve compression effectiveness and to lessen complexity of calculations. Contribution to this module is the same as above mentioned cropping module. Utilizing circle boundaries, the region of interest is determined. Crop and Mask is exhibited in Figure 3.

a)



Figure 3 : a) Cropping Module b) Masking Module

\subsection{JPEG 2000:}

PEG (Joint Photographic Experts Group) 2000 picture compression module is utilized to decrease the picture size avoiding any information loss. The open source module is a conventional one in which it supports many formats. Since picture will be retrieved in a raw format and subsequently converted to J2k (JPEG 2000) format, support for every other configuration will be discarded. JPEG 2000 OSS (Open Source Software) code comprises of both $9 / 7$ and $5 / 3$ wavelet change.

A snapshot of the prototype device can be seen in Figure 4. Parameters such as focus, exposure and a timer are seen to the user. When the Exposure shows OK and focus crosses a preset limit, the picture is captured. The separation distance between the eye of the user and the camera, relies upon the nature of lens utilized.

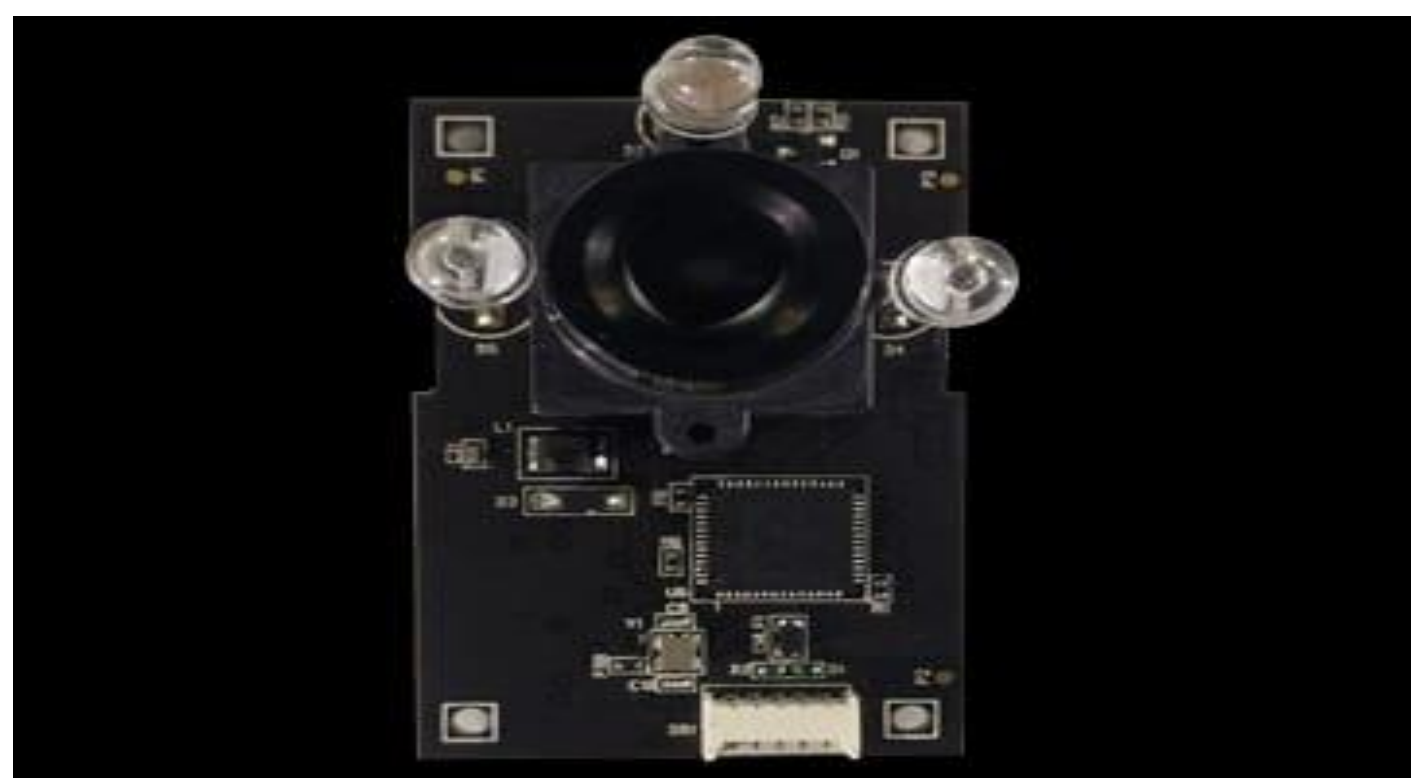

Figure 4 : Snapshot of Prototype 
Journal of Innovative Image Processing (JIIP) 2020)

Vol.02/ No. 03

Pages: $147-155$

https://www.irojournals.com/iroiip/

DOI: https://doi.org/10.36548/jiip.2020.3.005

\section{Results and Discussion}

The final output shown on an external display can be seen in Figure 5. This is the cropped and masked image that is used for further processing.

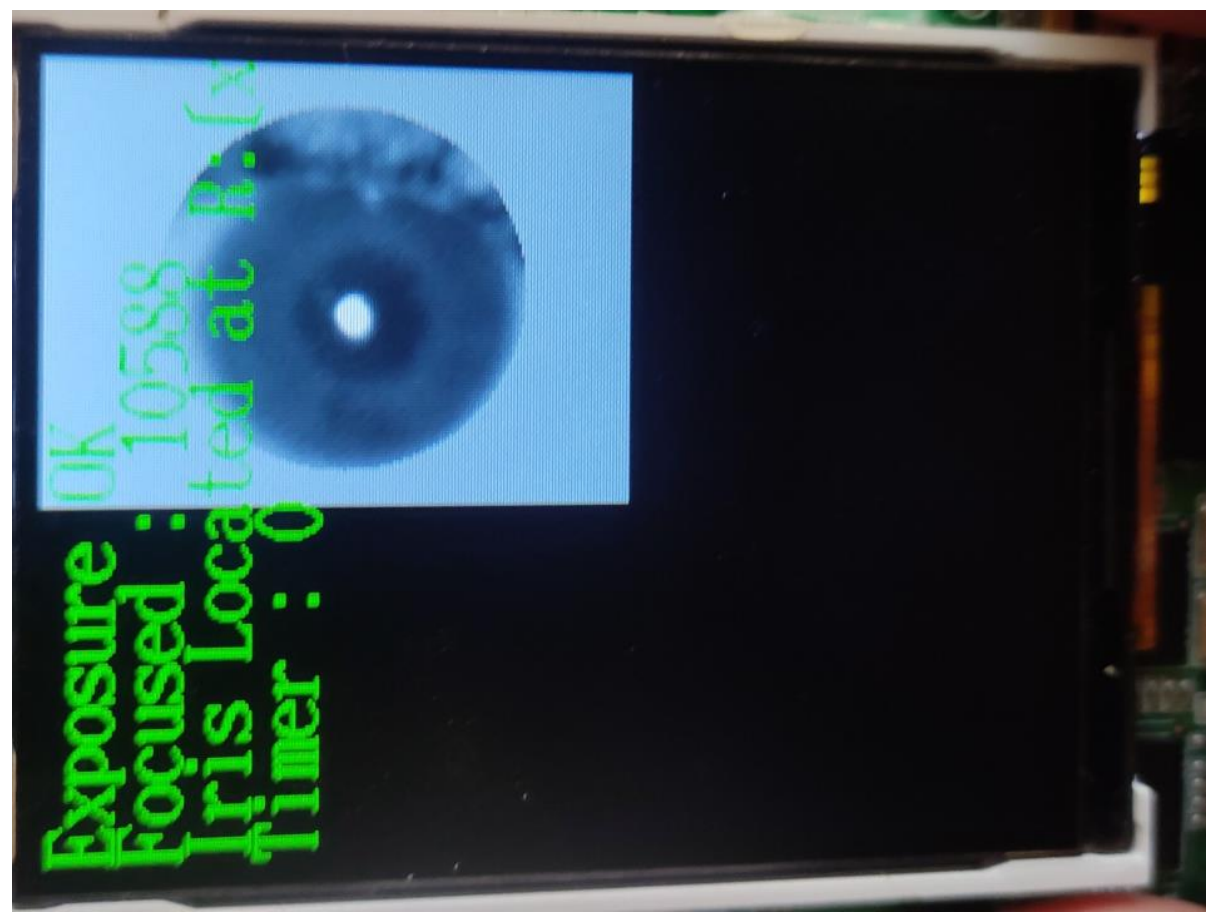

Figure 5 : Final Output

Table 4 shows the breakup of the time taken for each individual process implemented, for experiments conducted using this prototype. As seen the total duration is less than 400 milliseconds, as compared to previously implemented methods which take at least a few seconds. The performance was calculated for image inputs of size 640 x 480 px. Cropped image outputs were found to be $400 \times 300$ px.

\begin{tabular}{|l|c|}
\hline \multicolumn{1}{|c|}{ Module } & Time (milliseconds) \\
\hline Pre Processing & 27 \\
\hline Auto Exposure Statistic (uses DRP) & 06 \\
\hline Median Filter (uses DRP) & 3.2 \\
\hline Binning (uses DRP) & 4.5 \\
\hline Circle Fitting (uses DRP) & 93 \\
\hline Crop and Mask (uses DRP) & 4 \\
\hline JPEG Compression & 226 \\
\hline
\end{tabular}


Journal of Innovative Image Processing (JIIP) 2020)

Vol.02/ No. 03

Pages: $147-155$

https://www.irojournals.com/iroiip/

DOI: https://doi.org/10.36548/jiip.2020.3.005

Post Processing

Table 4 : Time consumed for individual modules

\section{Conclusion}

After considering the existing systems for iris image capture, segmentation and localization, this paper suggests a unique portable hardware solution. In it, the image processing is made quicker by an estimated 10 times. The RAM utilization is also significantly decreased from 1 to 2 GB (Giga Bytes) as used in a traditional CPU, to approximately $2 \mathrm{MB}$ (Mega Bytes). The future enhancements for this prototype are:

- To make it more cost effective and at the same time use high quality lenses, to enable capturing the image from further distances.

- To use hybrid image processing algorithms to further increase accuracy as well as reduce space and time complexity.

\section{Acknowledgement}

The work reported in this paper is supported by PathPartner Technology Private Limited (www.pathpartnertech.com) as well as Renesas Electronics (www.renesas.com), as industry collaborators.

\section{References}

[1] Smaran S. Rao, R Shreyas, Gajanan Maske, Antara Roy Choudhury, "Survey of Iris Image Segmentation and Localization", Fourth International Conference on Computing Methodologies and Communication (ICCMC), IEEE XPLORE, Mar 2020

[2] Rechu Sharma, Vaneet Mohan, "Biometric Identification Using Iris Recognition System", International Journal of Computer Application, March - April. 2016

[3] Supriya G, Srinivas Halvi, NT Deshpande, "Efficient Iris Recognition by Fusion of Matching Scores obtained by Lifting DWT and Log-Gabor methods of Feature Extraction”, International Journal of Applied Research, 2015

[4] Arindom Hazra, Manas Bhattacharjee, Nafisha Parween, Ridhi Sarkar, Writi Mitra, SK Bandyopadhyay, "Person identification using human iris recognition", International Journal of Applied Research, 2017

[5] Vince Thomas, Nitesh V. Chawla, Kevin W. Bowyer, Patrick J. Flynn, "Learning to predict gender form iris images"

[6] Ms. Sruthi.T.K, "Fast and Efficient Automated Iris Segmentation by Region Growing”, International Journal of Computer Science and Mobile Computing, Jun 2013

[7] S. Joshua Kumaresan, J. Raja Paul Perinbam, D. Ebenezer, "Person Identification with Iris Recognition Based on Generalized Structure Tensor”, Middle-East Journal of Scientific Research, 2015

[8] A Shakin Banu, C Christy Vimilitha, S Divya Bharathi, P Mathankini, "Iris Recognition using Daisy Descriptor", International Journal of Engineering Research and Science \& Technology, Apr 2015

[9] Anandhi, Dr. M. S. Josephine, Dr. V. Jeyabalaraja, S. Satthiyaraj, "Iris Segmentation and Detection System for Human Recognition Using Canny Detection Algorithm”, International Journal of Advanced Research, 2015

ISSN: 2582-4252 (online)

Submitted: 18.05.2020

Accepted: 30.06.2020

Published: 06.07.2020 
Journal of Innovative Image Processing (JIIP) 2020)

Vol.02/ No. 03

Pages: $147-155$

https://www.irojournals.com/iroiip/

DOI: https://doi.org/10.36548/jiip.2020.3.005

[10] Patnala S. R. Chandra Murthy, E. Sreenivasa Reddy, I. Ramesh Babu, "Iris Recognition system using Fractal Dimensions of Haar Patterns", International Journal of Signal Processing, IMage Processing and Pattern Recognition, Sep 2009

[11] Shrishti Pardhi, Sahana Gajala Qureshi, "Design and Implementation of Iris Recognition System Using Morphological Bridged Canny Edge Detection and KNN Classifier", International Journal of Engineering and Computer Science, Jun 2015

[12] K. Rajasri, S. Sathiyadevi, S. Tamilarasi, "New Algorithm and Indexing to Improve the Accuracy and Speed in Iris Recognition", International Journal of Research and Development, Oct 2012

[13] Mrigana Walia, Dr. Shaily Jain, "Iris Recognition System Using Circular Hough Transform", International Journal of Advanced Research in Computer Science and Management Studies, Jul 2015

[14] Humayan Kabir Rana, Md. Shafiul Azam, Mst. Rashida Akhtar, Julian M.W. Quinn, Mohammed Ali Moni, "A Fast Iris Recognition System through Optimum Feature Extraction", PeerJ Computer Science 5:e184

[15] Richard Yew Fatt Ng, Yong Haur Tay, Kai Ming Mok, "A Review of Iris Recognition Algorithms", International Symposium on Information Technology, Aug. 2008 